\title{
ЭМИГРАЦИЯ НЕМЦЕВ ДО И ПОСЛЕ РАСПАДА СССР В ГЕРМАНИЮ. ИНТЕГРАЦИЯ И ЕЁ РЕЗУЛЬТАТЫ
}

\begin{abstract}
Аннотация. В статье рассматривается эмиграция в Германию этнических немцев до и после распада СССР. Подробно разбираются эмиграџия из России и Казахстана. Выявляются причины эмиграчии, периоды, динамика. Анализируются категории эмигрантов, их успешность в интеграции в немецкое общество. Немецкая эмиграция из стран бывшего Советского Союза сегодня себя практически исчерпала. С 2005 г. Германия принимает только тех, кто сдаст необходимый языковой минимум. С одной стороны, это сократило поток поздних переселенщев, с другой, позволило принимать людей, имеющих хорошие шансы на интеграцию.
\end{abstract}

Ключевые слова: эмиграчия, этнические немџы, поздние переселенџы, интеграџия, русские немџь.

Германия является лидером по количеству эмигрантов из стран бывшего СССР. По этому показателю она заметно опережает США и Израиль. Это объясняется тем, что в СССР проживало большое количество этнических немцев, многие из которых предпочли вернуться на историческую родину. История эмиграции немцев прослеживается с 1951 г., когда их определённой части разрешили покинуть СССР. После распада страны поток усилился и основными странами эмиграции стали Россия и Казахстан, т.к. именно в них проживала подавляющая часть немецкого населения - около 90\%. Эмиграция, кроме экономических причин, определялась невозможностью восстановления автономии в Поволжье, родине для многих советских немцев. После переезда около трети не преуспели на новом месте. Часть из них решила вернуться обратно, многие остались. Как показало исследование, среди тех, кто оказался слабо интегрирован, нашлось немало сторонников партии «Альтернатива для Германии» (АдГ).

\section{Формирование немецкого меньшинства в СССР и причины его эмиграции после распада СССР}

Формирование на территории стран бывшего СССР немецкой диаспоры имеет исторические корни: этнические немцы приглашались для освоения территории Российской империи около 250 лет назад. «Манифест Екатерины II о позволении иностранцам селиться в России и свободном возвращении русских людей, бежавших за границу» имел своей целью заселить и освоить пустующие земли, как старые, так и присоединённые в ходе войн с Турцией ${ }^{1}$. Кроме хозяйственного развития губерний и распространения эффективных технологий, стра-не было важно получить крепкую сплочённую общность, сумеющую защитить террито-

(C) Сейткалиев Роман Максутович - младший научный сотрудник НИ ИМЭМО им. Е.М. Примакова РАН. Aдрес: 117997, Россия, Москва, ул. Профсоюзная, д. 23.E-mail: seytkaliev_roman@mail.ru. DOI: DOI: http://dx.doi.org/10.15211/vestnikieran620182

${ }^{1}$ Манифест императрицы Екатерины II о позволении иностранцам селиться в России и свободном возвращении русских людей, бежавших за границу. URL:http://wolgadeutsche.net/history/manifest-1762.htm (дата обращения: 10.12.2018). 
рию от врага. Два потока колонистов сформировались в процессе переселения: в Поволжье с 1764 г. и в Новороссию с 1783 г. Переезжали также французы, шведы, швейцарцы, но больше всего было немцев из разных земель Германии ${ }^{1}$. Имели место случаи их эмиграции из Российской империи. Однако они не приобретали массового характера, и к концу XIX в. в Российской империи проживало около 1380 тыс. носителей немецкого языка.

Советский период в жизни немцев был противоречивым. На раннем этапе им были предоставлены права на национальные территориальные объединения - от Автономной Советской Социалистической Республики (АССР) Немцев Поволжья до национальных районов и сельсоветов в местах компактного проживания. От районов и сельсоветов в конце 1930-х гг. отказались, тогда как АССР Немцев Поволжья сохранялась вплоть до 7 сентября 1941 г. - начала насильственной депортации ${ }^{2}$. Немцев обвинили в пособничестве врагу и выслали их вглубь страны, преимущественно в районы Северного Казахстана и Западной Сибири. Во время и после войны именно там сконцентрировались основные массы немецкого населения $(40,7 \% \text { и } 32,6 \%)^{3}$. Трудоспособное население было призвано в так называемую «трудовую армию», а в самих местах проживания был установлен режим спецпоселений (его отменили только в 1956 г.). Законодательное закрепление немцев на этих территориях оформилось уже после войны, приведя к их длительной территориальной и социальной изоляции. В 1948 г. был принят указ Президиума Верховного Совета СССР, закрепляющий депортированные народы в местах высылки. В тексте заявлялось, что переселение произошло навечно, без права возврата к прежним местам высылки ${ }^{4}$ В 1972 г. ограничения в выборе места жительства были сняты, однако их возвращению на исконные территории в центре СССР всячески препятствовали. Ограничения, наложенные на немцев, спровоцировали их переезд в ФРГ. Но массового оттока можно было избежать, вернув им их «родину» в Поволжье. За восстановление АССР Немцев Поволжья выступало Всесоюзное общество советских немцев «Возрождение», однако результатов это не принесло. Немецкое население при посредничестве ФРГ, которое обещало наладить инфраструктуру в местах возвращения, вели переговоры с российскими властями. Формально российские власти были не против возвращения немцев на исторические места, однако конкретных предложений по выделению земли и обустройства быта не имели. Также они были против автономии, говоря, что она невозможна, пока немецкое население не будет превышать 90\% населения территории 5 . Ранее выдвигалась идея создания немецкой автономии в северном Казахстане, однако и эта идея не воплотилась ${ }^{6}$. После этого немцы потеряли всякую надежду на культурную или административную автономию, что, несомненно, наряду с экономической нестабильностью, подогрело их эмиграционные настроения.

\section{Эмиграция немцев во времена СССР и после распада}

\footnotetext{
${ }^{1}$ Начало и завершение или ... снова начало? Вывоз немцев в России и выезд в Германию. МИГ. Городская газета (г. Волгоград). URL:http://wolgadeutsche.net/bibliothek/mig/mig_14_12_1992.htm (дата обращения: 11.12.2018).

2 Указ Президиума Верховного Совета СССР «О переселении немцев, проживающих в районах Поволжья». URL: http://wolgadeutsche.net/history/ukas_28_08_1941.htm (дата обращения: 13.12.2018).

${ }_{3}^{3}$ Малова Н.А. Миграционные процессы в немецкой автономии на Волге, 1918-1941 гг.: дис. канд. ист. наук: 07.00.02: [Место защиты: Саратовский государственный университет им. Н.Г. Чернышевского] - Саратов. 2001. $-276 \mathrm{c}$.

${ }^{4}$ Указ Президиума Верховного Совета СССР от 26 ноября 1948 г. «Об уголовной ответственности за побеги из мест обязательного и постоянного проживания лиц, выселенных в отдалённые районы Советского Союза в период Отечественной войны». URL:http://wolgadeutsche.net/history/ukas_26_11_1948.htm (дата обращения: 15.12. 2018).

5 Россия без русских немцев? URL:https://yeltsin.ru/uploads/upload/newspaper/1992/izv01_03_92/index.html (дата обращения 25.12.2018).

6 «Переселению подлежат все без исключения немцы, в том числе члены ВКП(б) и ВЛКCM». URL: https:// pravo.ru/news/view/123033/ (дата обращения: 17.12.2018).
} 
Одна из первых волн эмиграции была связана с теми немцами, кто во время войны попал под оккупацию до депортации и получил немецкий паспорт. Их возвращение было одним из пунктов переговоров К. Адэнауэра во время его визита в 1950 г. В 1951 г. В ФРГ уехали 1,8 тыс. человек. Далее выезд регулировало правительство, в среднем 6-7 тыс. в год ${ }^{1}$. Подстегнуло эмиграцию очередное послабление внутренних правил в 1972 г., ограничивавших немцев в выборе места проживания и невозможности свободно перемещаться по территории СССР. Для эмиграции советского периода характерна эпизодичность, подверженная внешнеполитическим решениям советского правительства и ответу на него других стран. Так, из-за ввода советских войск в Афганистан эмиграция приостанавливалась в 1979-1986 гг. Всего уехало с 1951 по январь 1988 г. 122,2 тыс. человек². С 1988 г. количество эмигрантов возрастало быстрыми темпами, которые ещё больше увеличились с 1991 г. с распадом страны.

В СССР количество немцев с 1979 по 1989 гг. возросло с 1936 тыс. до 2039 тыс. чел. В 1989 г. в Казахстане согласно переписи проживало 946,9 тыс. немцев, в 1999 г. их было уже 353,4 тыс., в 2009 г. - 220,9 тыс. Прямой отток составил 726 тыс. - самый большой показатель в СНГ (см. табл. 1). В России по данным переписей 2002 г. и 2010 г. немецкое население сократилось с 597,2 тыс. до 394,1 тыс. человек ${ }^{3}$. Немцев в других странах, образовавшихся после распада СССР, было и того меньше, не более 3 тыс. в Белоруссии и в среднем по 1,5 тыс. в балтийских странах. После открытия границ они практически все выехали в Германию.

Таблица 1

Число немцев: данные переписей (тыс. чел.)

\begin{tabular}{|l|c|c|c|c|}
\hline & 1979 & 1989 & 1999 & 2009 \\
\hline РСФСР / Россия & 790,8 & 842,3 & $597,2(2002$ г.) & $394,1(2010$ г.) \\
\hline Казахская ССР / Казахстан & 900,2 & 946,9 & 353,4 & 220,9 \\
\hline Киргизская ССР / Киргизия & 101 & 102 & 21 & 9,5 \\
\hline Таджикская ССР / Таджикистан & 38,9 & 32,7 & 0 & 0 \\
\hline Украинская ССР / Украина & 34,1 & 37,8 & \multicolumn{2}{|c|}{$33,3(2001$ г.) } \\
\hline Узбекская ССР / Узбекистан & 39,5 & 39,8 & $7,8(2000$ г.) & $0(2013$ г.) \\
\hline Молдавская ССР / Молдавия & 11,4 & 7,3 & $-(2004$ г.) & $-(2014$ г.) \\
\hline
\end{tabular}

Данные обобщены на основе национальных ведомств статистики (Росстат, Казстат, национальный статистический комитет Кыргызской Республики, агентство по статистике при президенте Республики Таджикистан, государственная служба статистики Украины, государственный комитет Республики Узбекистан по статистике, национальное бюро статистики (Республика Молдова)).

Из Казахстана в 1990-е гг. эмигрировала большая часть этнических немцев страны. Динамика в 2000-е гг. постепенно снижалась, но в 2013 г. опять пошла вверх (см. табл. 1 и табл. 2).

Таблица 2

Статистика эмиграции граждан Республики Казахстан в Германию в 2000-2017 гг.

\begin{tabular}{|c|c|c|c|c|c|c|c|c|c|c|c|c|c|c|c|c|c|}
\hline 2000 & 2001 & 2002 & 2003 & 2004 & 2005 & 2006 & 2007 & 2008 & 2009 & 2010 & 2011 & 2012 & 2013 & 2014 & 2015 & 2016 & 2017 \\
\hline \multicolumn{18}{|c|}{ Эмиграция } \\
\hline 35938 & 38469 & 32832 & 22520 & 17221 & 10299 & 2528 & 1848 & 1590 & 1339 & 974 & 971 & 818 & 1206 & 2179 & 2196 & 2679 & 2966 \\
\hline \multicolumn{18}{|c|}{ Иммиграция } \\
\hline 548 & 599 & 603 & 776 & 764 & 675 & 615 & 562 & 548 & 386 & 366 & 307 & 212 & 169 & 176 & 222 & 214 & 225 \\
\hline
\end{tabular}

\footnotetext{
${ }^{1}$ Начало и завершение или ... снова начало? Вывоз немцев в России и выезд в Германию. МИГ. Городская газета (г. Волгоград). URL :http://wolgadeutsche.net/bibliothek/mig/mig_14_12_1992.htm (дата обращения:18.12.2018). ${ }_{2}$ Россия без русских немцев? URL:https://yeltsin.ru/uploads/upload/newspaper/1992/izv01_03_92/index.html (дата обращения: 25.12.2018).

${ }^{3}$ Но это не говорит о том, что вся разница в 203,1 тыс. человека переехала в Германию. Изменение количества немцев в России зависело от иммиграции из других бывших советских республик. Другая часть при переписи определила свою национальную принадлежность как русские.
} 
Источник: stat.gov.kz.

По данным российского статистического ежегодника в период с 1990 по 1999 гг. из страны в Германию выехало 570,8 тыс. человек. По данным немецкой статистики более $65 \%$ эмигрантов с России были представлены этническими немцами. Среди эмигрантов из Казахстана этот показатель ещё выше. Бо́льшая часть эмигрантов состояла из этнических немцев, поэтому в статистике Германии они не отражались. Начиная с 2000 г. количество этнических эмигрантов начинает сокращаться, и в то же время увеличиваться доля русских $-40,1 \%$ в 2000 г. ${ }^{1}$ В 2015 г. в Германии насчитывалось свыше 1 млн 200 тыс. жителей, которые или сами или хотя бы один из их родителей прибыли из России. Из Казахстана таковых насчитывалось 737 тыс. $^{2}$

\section{Интеграция поздних переселенцев в Германии}

По замыслам властей интеграция поздних переселенцев должна была пройти безболезненно. Им предоставили ряд преимуществ, которых не было ни у какой из групп эмигрантов, а именно гражданство, бесплатное прохождение интеграционного курса, признание профессиональной и академической квалификаций, рабочего стажа и службы в армии. На первое время им выделялась материальная помощь и возмещение стоимости переезда. Поддержка очень серьёзная, но, как показало время, она не сыграла решающую роль. Куда большее влияние на интеграцию оказали факторы субъективные.

М.А. Савоскул предлагает выделять три категории переселенцев, которые отличаются друг от друга по степени интегрированности в немецкий социум: это ранние переселенцы, которые определяют себя немцами и никем другим; переселенцы, которые определяют себя как русские немцы; и переселенцы с проблемами в самоидентификации ${ }^{3}$. У первых и вторых не возникло проблем с интеграцией. Первые, как правило, прибыли в первой волне миграции в начале 1990-х гг. и 75\% из них хорошо знали немецкий. Вторые, несмотря на интеграцию в местный социум, сохранили и поддерживают контакты со старыми друзьями, активно участвуют в работе русских клубов. Определённые проблемы имеет только третья группа, самая многочисленная. Их социальные контакты с коренными немцами ограничены и они предпочитают общаться с такими же выходцами из стран бывшего СССР на русском языке. Устройство на работу по прежней специальности часто невозможно из-за скудного знания немецкого. По подсчётам властей в 2007 г. треть поздних переселенцев были безработными ${ }^{4}$. Также власти признают, что не все поздние переселенцы работают по специальности. Чаще всего проблемы возникают с признанием дипломов у инженеров, врачей, учителей. В их случае потеря социального статуса представляется безвозвратной. Основной причиной трудностей третьей группы поздних переселенцев стало их обособление от коренного населения. Способствовала этому отмена в 2000 г. нормы, принуждающей поздних переселенцев жить в определённых местах. C её отменой переселенцы начали самостоятельно выбирать место, зачастую там, где уже обосновались русскоговорящие земляки. В районах компактного проживания они наладили привычный им уклад жизни, там распространены русские магазины, клубы, диско-

\footnotetext{
${ }^{1}$ Савоскул М.С. Эмиграция из России в страны дальнего зарубежья в конце XX - начале XXI века. Вестник Московского Университета. Сер. 5 География. 2016. №2. С. 44-54.

${ }_{2}^{2}$ Migrationsbericht 2015. Referat Öffentlichkeitsarbeit. Bundesministerium des Innern. Berlin. 2016. P. 162.

${ }^{3}$ Савоскул М.С. Российские немцы в Германии: интеграция и типы этнической самоидентификации (по итогам исследования российских немцев в регионе Нюрнберг - Эрланген). Этнографическое обозрение. 2004. №4. С. 99.

4 Треть живущих в Германии переселенцев не имеет работы. URL:https:/www.dw.com/ru/треть-живущих-вгермании-переселенцев-не-имеет-работы/а-2443886 (дата обращения: 15.12.2018).
}

Научно-аналитический вестник ИЕ РАН, 2018, №6 
теки, язык общения в которых соответственно русский ${ }^{1}$.

В подобных районах особенно часто на прошедших выборах в Бундестаг голосовали за партию АдГ. Предстоит разобрать в какой мере проблемы в интеграции сказались на политических предпочтениях поздних переселенцев.

\section{Поддержка русскоязычного населения Германии партии «Альтернатива для Германии»?}

На выборах в Бундестаг партия АдГ набрала 12,6\% голосов, что позволило ей стать третьей по силе партией в парламенте, и получила 94 места. На территориях бывшей Восточной Германии за неё проголосовали 21,5\% жителей. Русскоязычные жители, по мнению экспертов, также активно голосовали за партию на выборах. В местах компактного проживания русских немцев на территориях старых западных земель АдГ получала 20, 30 и даже 40\%. В городе Пфорцхайм - 24,2\%, а в районе Хайдах $-44 \%{ }^{2}$. Традиционно русскоязычные немцы голосовали за ХДС/ХСС со времён Г. Коля, который пригласил их в Германию, однако после миграционного кризиса они разочаровались в политике партии. АдГ первой из партий стала использовать предвыборные брошюры на русском языке, с критикой миграционной системы. В рамках той же политики привлечения голосов русскоязычных немцев она провела Российский конгресс в земле Саксония-Ангальт. В своей внешнеполитической программе она выступила за признание Крыма российским и за снятие санкций с РФ, однако не эти положения привлекают русскоязычных сторонников. Они больше интересуются миграционной политикой, тем большим вниманием, которое оказывается пришлым, в то время как себя они считают обделёнными. Некая ревность к мигрантам проявляется и в вопросе возможности перевезти свои семьи, так как у многих русских немцев еще остались родственники в России и в странах СНГ от смешанных браков, не подходящих под закон о поздних переселенцах. По мнению русскоязычных немцев, они имеют больше прав на переселение в Германию.

До выборов эксперты говорили о 45\%-ной поддержке русских немцев партии, к выборам они значительно упали и составили средние по стране $14 \%$. Выборы показали, что русские немцы проголосовали за партию в среднем чаще на 1,7 проц. пункта по сравнению с коренными немцами. В случае с районами компактного проживания русских немцев, рекордно проголосовавших за АдГ, организации русских немцев, опровергающих свои симпатии к партии, высказались, что это проблема качества голосующих, людей более взрослых и менее квалифицированных, так и не съехавших с социальных квартир, выданных им при переезде. Правильнее в этом случае будет определить проголосовавших, скорее не как русскоязычных, а как русскоговорящих, использующих в повседневной жизни больше русского, чем немецкого, и не располагающие, соответственно, высокими доходами. Поэтому голосование за АдГ, скорее, стоит определить социально-экономическим вопросам, а не культурным.

\section{Заключение}

Немецкая эмиграция из стран бывшего Советского Союза сегодня себя практически исчерпала. С 2005 г. Германия принимает только тех, кто сдаст необходимый языковой минимум. С одной стороны, это сократило поток поздних переселенцев, с другой, позволило принимать людей, имеющих хорошие шансы на интеграцию. В случае с живущими в стране

\footnotetext{
${ }^{1}$ Савоскул М.С. Российские немцы в Германии: интеграция и типы этнической самоидентификации (по итогам исследования российских немцев в регионе Нюрнберг - Эрланген). Этнографическое обозрение. 2004. №4. С. 99.

${ }_{2}^{2}$ Российские немцы: Не изображайте всех нас избирателями АдГ! 20.09.2017. URL: https://www.dw.com/ru/ pocсийские-немцы-не-изображайте-всех-нас-избирателями-адг/а-40603854 (дата обращения: 10.10.2018).
}

Научно-аналитический вестник ИЕ РАН, 2018, №6 
русскими немцами их интеграция так и останется неоконченной. В лучшем случае только их дети смогут стать своими в Германии.

\section{Список литературы}

Денисенко М.Б. Эмиграция из России по данным зарубежной статистики. Мир России. 2003. №3. С. 157-169.

Малова Н.А. Миграционные процессы в немецкой автономии на Волге, 1918-1941 гг.: дис. канд. ист. наук: 07.00.02: [Место защиты: Саратовский государственный университет им. Н.Г. Чернышевского] - Саратов. 2001. - 276 с.

Савоскул М.С. Российские немцы в Германии: интеграция и типы этнической самоидентификации (по итогам исследования российских немцев в регионе Нюрнберг - Эрланген). Этнографическое обозрение. 2004. №4. С. 99.

Савоскул М.С. Эмиграция из России в страны дальнего зарубежья в конце XX - начале XXI века. Вестник Московского Университета. Сер. 5 География. 2016. №2. С. 44-54.

Migrationsbericht 2015. Referat Öffentlichkeitsarbeit. Bundesministerium des Innern. Berlin. 2016. P. 276.

\section{References}

Manifest imperatricy Ekateriny II o pozvolenii inostrancam selit'sya v Rossii i svobodnom vozvrashchenii russkih lyudej, bezhavshih za granicu. URL: http://wolgadeutsche.net/history/ manifest-1762.htm (accessed: 10.12.2018).

Nachalo i zavershenie ili ... snova nachalo? Vyvoz nemcev v Rossii i vyezd v Germaniyu. MIG. Gorodskaya gazeta (g. Volgograd). URL: http://wolgadeutsche.net/bibliothek/mig/mig_14_12_ 1992.htm (accessed: 11.12.2018).

Ukaz Prezidiuma Verhovnogo Soveta SSSR «O pereselenii nemcev, prozhivayushchih v rajonah Povolzh'ya». URL: http://wolgadeutsche.net/history/ukas_28_08_1941.htm (accessed: 13.12.2018).

Ukaz Prezidiuma Verhovnogo Soveta SSSR ot 26 noyabrya 1948 g. «Ob ugolovnoj otvetstvennosti za pobegi iz mest obyazatel'nogo i postoyannogo prozhivaniya lic, vyselennyh $\mathrm{v}$ otdalennye rajony Sovetskogo Soyuza v period Otechestvennoj vojny» URL: http://wolgadeutsche.net/history/ ukas_26_11_1948.htm (accessed: 15.12.2018).

Rossiya bez russkih nemcev? URL: https://yeltsin.ru/uploads/upload/newspaper/1992/izv 01_03_92/index.html (accessed: 25.12.2018).

«Pereseleniyu podlezhat vse bez isklyucheniya nemcy, v tom chisle chleny VKP(b) i VLKSM». URL: https://pravo.ru/news/view/123033/ (accessed: 17.12.2018).

Denisenko M.B. Istoricheskie i aktual'nye tendencii ehmigracii iz Rossii. URL: http://www. mirprognozov.ru/prognosis/society/istoricheskie-i-aktualnyie-tendentsii-emigratsii-iz-rossii/ (accessed: 01.10.2018).

Tret' zhivushchih v Germanii pereselencev ne imeet raboty. URL: https://www.dw.com/ru/tret'zhivushchih-v-germanii-pereselencev-ne-imeet-raboty/a-2443886 (accessed: 15.12.2018).

Rossijskie nemcy: Ne izobrazhajte vsekh nas izbiratelyami AdG! 20.09.2017. URL: https://www.dw.com/ru/rossijskie-nemcy-ne-izobrazhajte-vsekh-nas-izbiratelyami-adg/a-40603854 (accessed: 10.10.2018). 


\section{Emigration of Germans before and after the Collapce of the USSR to Germany. Integration and its Results}

Author. Roman Seytkaliev, Junior Researcher of Institute of World Economy and International Relations. Address: Primakov National Research Institute of World Economy and International Relations, Russian Academy of Sciences. Address: 23, Profsoyuznaya str., Moscow, Russia, 117997. E-mail: seytkaliev_roman@mail.ru.

Abstract: The article discusses the emigration of ethnic Germans to Germany before and after the collapse of the USSR. Exported in detail emigration from Russia and Kazakhstan. Reveals the causes of emigration, periods, dynamics. The categories of emigrants, their success in integration into German society are analyzed.

Key words: emigration, ethnic Germans, late immigrants, integration, Russian Germans.

DOI: DOI: http://dx.doi.org/10.15211/vestnikieran620182 